\title{
IEBOOK-based Experimental Operation Platform of Computer Basic Course
}

\author{
https://doi.org/10.3991/ijet.v12.i09.7484 \\ Rong Niu, Zhu Zhang $\left({ }^{\varpi}\right)$ \\ Tarim University, Alar, Xinjiang \\ 772278338 @qq.com
}

\begin{abstract}
With the development of information technology, educators combine the teaching contents of basic computer knowledge with the abundant materials available online, having raised the interestingness and attraction of the teaching practice of computer basic course. This paper aims to design an IEBOOK-based experimental operation platform of computer basic course which can overcome the defects of traditional experimental operation platform of inconvenience and less abundance of contents by combining IEBOOK software and an interactive display technology (including input module, picture processing module, touch screen, image addition module, and output module) of electronic courseware. The results show that the IEBOOK-based experimental operation platform effectively combine classroom teaching and after-class review, Q\&A and resources exchange, and largely raise students' interest in computer basic course learning, self-management sills, and communicative competence via mobile devices such as mobile phone and tablet PC.
\end{abstract}

Keywords-Multimedia technology, IEBOOK, acquisition via touch control, picture processing, experimental operation platform

\section{$1 \quad$ Introduction}

Multimedia technology [1] refers to a human-computer interaction technique that can fully display information formed by comprehensively processing text, image, voice and animation via computer as carrier. Presently, applying multimedia system in teaching has become the main mode of classroom teaching in most schools. Multimedia teaching is helpful to greatly enrich classroom teaching forms, stimulate students' learning interest and improve students' comprehensive ability in various ways, facilitate teachers in controlling the pace of teaching and improving teaching effect. The hardware and software of multimedia teaching have been largely enriched, and multimedia teaching technology has been largely developed. But there still are problems in the application of multimedia technology in teaching. In China, the computers of most teachers are installed with Windows system, so that they can present teaching materials with PowerPoint (PPT) only. Although the basic display purposes can be achieved with this software, it is a complicated and difficult job to post comments or remarks on the displayed contents during the displaying process due to the limitations 
of this software. Thus, to work out a method of adding required contents to the PPT in display easily in a dynamic way becomes an urgent problem to be solved in the application of multimedia technology in teaching.

IEBOOK technology is useful for display contents consisting of text, image and voice with computer as carrier to tackle teaching tasks. Besides, IEBOOK also integrates the idea of cloud design into teaching process, so that anyone can participate in the online design process of teaching contents via the IEBOOK software in the process of displaying teaching contents to update the teaching contents from time to time, and students can voice their views on the teaching contents and exchange their feelings with each other with the module of interactive community of this software. Thus, the application of IEBOOK in teaching platform is helpful to overcome the defects of PPT.

\section{State of the art}

Modern experimental operation platform refers to a device of realizing display of teaching contents with modern multimedia technology in teaching practice. Such type of experimental operation platforms are built with computer as the hardware foundation, and are for achieving the desired teaching objectives via text, image, voice and video [1]. With the progressive development of computer technology, top-level computer talents become in a large demand. Accordingly, it needs to form a complete education and teaching system for cultivation of computer talents. Through the practice of computer teaching in other countries, sound modern experimental operation platforms for computer course teaching have been developed. Piazolo et al. [2] had designed a visualized teaching system with specific functions that can stand without computer based on field-programmable gate array (FPGA). Gonçalves et al. [3] showed a scalable platform that is designed from nothing to support teaching laboratories of embedded systems. The complexity of platform can increase to provide more functionalities together with student's educational evolution. An I2C bus can guarantee the continuity of functionalities among modules, and the modern experimental operation platform is helpful to improve students' ability of comprehending textbook knowledge. The MOOCs platform emerged in China recently is being applied in basic experimental teaching of computer course, and primary effects have been achieved [4]. Li [5] introduced the teaching mode of cloud space into the basic experiment teaching of computer course, forming teacher's teaching model and students' learning mode in reliance upon cloud space based on network to cultivate students' self-study ability and interpersonal communication ability, and stimulate students' learning interest. Good teaching effect had been achieved. Basic experimental curriculum of college computer is one of the key teaching points, and the key to cultivation of new type application-oriented talents [6]. However, the teaching experimental operation platforms of computer course widely applied in China are mainly implemented in such a form that teachers give lessons with the aid of PPT, students learn knowledge via the PPT and consolidate the learned knowledge by means of exercise on the computer, the interaction between teachers and students is limited to classroom teaching 
only, and the teaching efficiency is low [7-8]. Although online teaching mode has been developed for a lot of courses such as computer course in China, such teaching mode is of slight difference from the traditional teaching mode of computer course; besides, PPT is indispensable for multimedia teaching, but PPT often comes with alone without any comments or remarks for interaction. Although the PPT can be modified with the computer, the job is complicated and it is hard to achieve the desired effect. For PPT display, teachers usually design the PPT first, and then display the PPT via large screen TV set connected with computer with the aid of mouse. This mode is convenient to realize PPT display, but it is complicated to add some contents in the process of displaying.

In view of this, it is urgent for us to build a modern comprehensive experimental operation platform that integrates lesson delivery, question answering and lesson preparation to reduce the complexity of communication and interaction between students and teachers, and facilitate teachers in lesson preparation and courseware sharing. Since IEBOOK is compatible with mobile devices such as mobile phone, tablet $\mathrm{PC}$, it can be applied in classroom teaching. Hence, this research is intended to build an IEBOOK-based modern teaching experimental operation platform that is in combination with interactive demonstration technology of electronic courseware, to provide a reference and idea for construction of similar experimental operation platforms in the future.

\section{Theoretical basis}

The modern experimental operation platform referred to in this paper mainly relates to two aspects: (1) IEBOOK software; (2) an interactive demonstration technology of electronic courseware.

\subsection{Cognitive learning theory}

According to the cognitive learning theory, teacher is the designer and implementer of pedagogical practices, and evaluator of students' learning effect. As long as teacher carefully screens and extracts teaching materials and platform to create favorable learning environment and conditions, and selects interest-stimulating teaching materials that help students' learning before learning activities are carried out, the desired teaching objectives can be achieved well. (Figure 1)

\subsection{Multiple intelligence theory}

In the multiple intelligence theory, an education view of integrated development and an education theory of lifelong learning have been put forward, which is of theoretical guiding significance to scientificity of teaching objectives, diversity of teaching mode, and diversification of teaching evaluation, and has a far-reaching effect on the reform of education and teaching. Gardiner's multiple intelligence theory enlightens us in the following aspects in teaching and education: 
1. To create various different scenarios: To create various different scenarios for learning activities suitable for students' personalities, and design learning activities suitable for students' intellectual development according to students' intelligent characteristics, to help students construct knowledge in a harmonious and relaxing environment.

2. To adopt various different teaching methods: Teacher should teach students in accordance of their aptitude with various different teaching methods and means, to help students develop in the proper direction. (Figure 2)

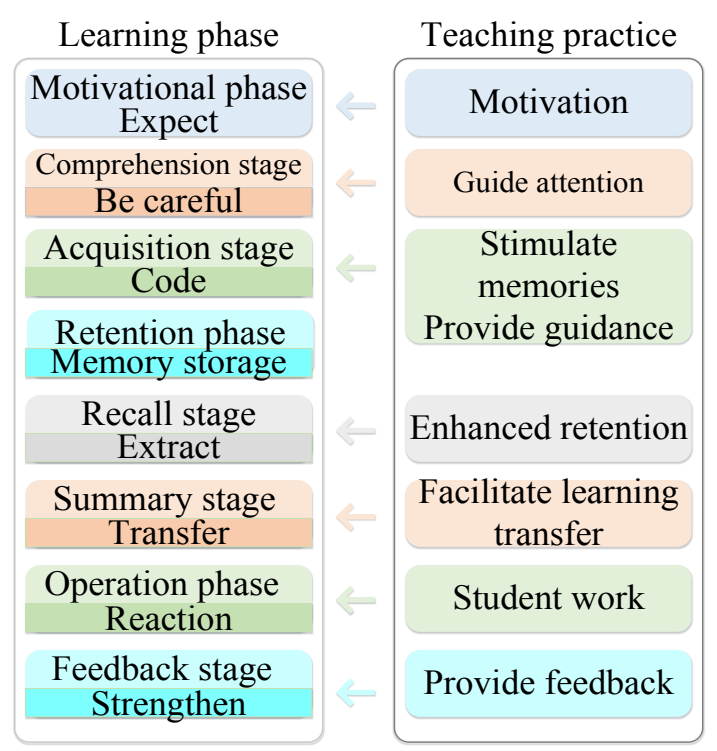

Fig. 1. Information processing mode of cognitive learning theory

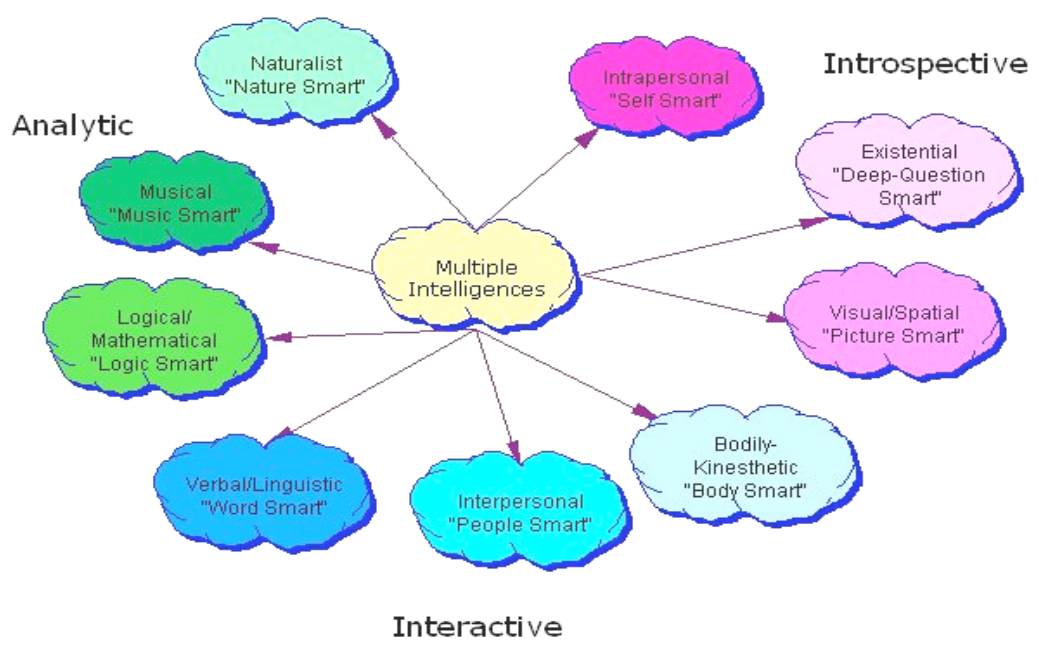

Fig. 2. Structure chart of multiple intelligence theory 


\subsection{IEBOOK software}

The IEBOOK selected for this paper is manufactured by Guangzhou Feitian Media Company. It is an interactive electronic journal platform software. IEBOOK, via new digital contents presented by means of video audio integration operation, provides various high-quality flash templates and page effects, makes learning process easy and simple, and is easy to operate for teachers.

\subsection{Interactive demonstration technology of electronic courseware}

By combining the demonstration of electronic courseware and the touch control function for demonstration of electronic courseware, it is easy to add contents during the demonstration of electronic courseware and record the presenter's gestures, to realize interactive demonstration of electronic courseware.

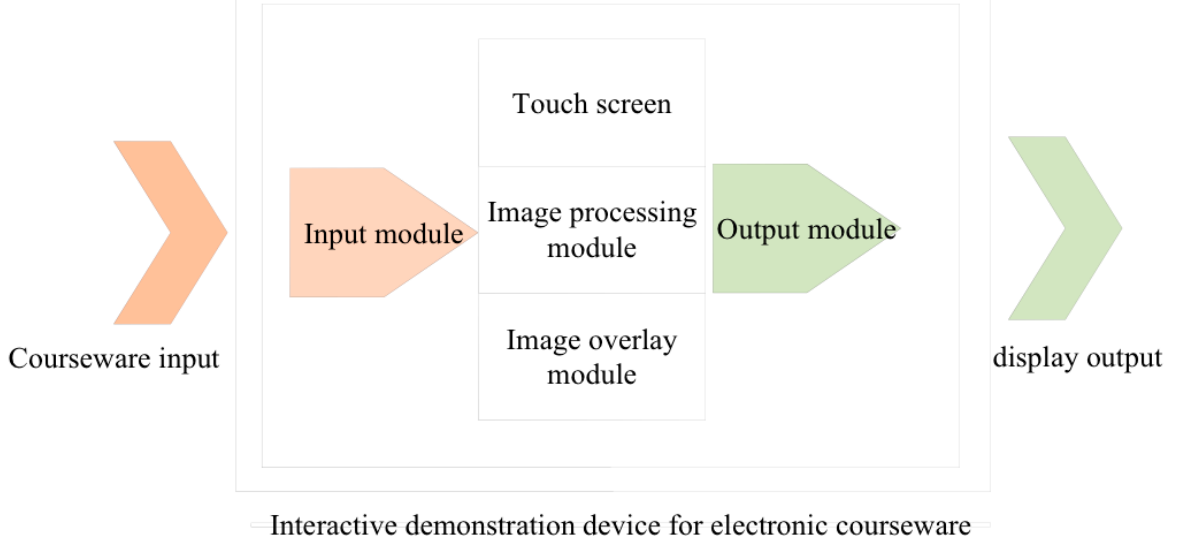

Fig. 3. Schematic diagram of interactive demonstration technology of electronic courseware

The most important part of the interactive demonstration technology of the electronic courseware is an interactive demonstration device of electronic courseware, which consists of the following modules:

1. Input module, which can be connected with an external computer terminal to input electronic courseware to be demonstrated.

2. Image processing module, which is connected with the input module and touch screen for converting the electronic courseware input via the input module into images for displaying on the screen.

3. Touch screen, which is connected with the image processing module. The images acquired by the image processing module can be transferred to the touch screen in real time way. Besides, this module can be used for recording user's touch track on the screen and feedback the touch track to the image processing module.

4. Image addition module, which is connected with the image processing module, can overlap the touch track recorded by the touch screen with the display image ac- 
quired by the image processing module to obtain the output result of the two modules, and feedback the output result to the image processing module.

5. Output module, which is connected with the image processing module to output the images displayed before and after overlapping to the external multimedia device.

Besides, in the whole process of image processing, the following formulas are needed to prevent that image processing from distortion.

$$
\begin{gathered}
\operatorname{Max} V+\operatorname{Mid} V+\operatorname{Min} V=\operatorname{Max} V^{\prime}+\operatorname{Mid} V^{\prime}+\operatorname{Min} V^{\prime}=B \\
(\operatorname{Mid} V-\operatorname{Min} V) /(\operatorname{Max} V-\operatorname{Min} V)= \\
\left(\operatorname{Mid} V^{\prime}-\operatorname{Min} V^{\prime}\right) /\left(\operatorname{Max} V^{\prime}-\operatorname{Min} V^{\prime}\right)=H
\end{gathered}
$$

The two formulas above are for keep the brightness and hue of the whole touch track image and electronic courseware image unchanged.

Based on the different angles and positions of touch graphics, the region of the new image can be determined in the following way only.

$$
\begin{aligned}
& x^{\prime}=x \cos \theta-y \sin \theta \\
& y^{\prime}=y \cos \theta+x \sin \theta
\end{aligned}
$$

\section{Construction of IEBOOK-based experimental operation platform of computer basic course}

For a complete teaching process, the construction of an experimental operation platform is the foundation for the teaching of computer basic course. To construct of a teaching experimental operation platform, the teaching contents, teaching objects, and teaching objectives should be combined organically, and the design and development of experimental operation platform should be carried out after proper task analysis, so as to achieve the most ideal teaching effect of computer basic course.

\subsection{Overall structure design of experimental operation platform}

An experimental operation platform has been built for the teaching of college computer basic course with IEBOOK software. For the modern experimental operation platform, not only IEBOOK software is employed, an interactive demonstration technology of electronic courseware presented in Chapter III is introduced into the experimental teaching of college computer basic course. This experimental operation platform can integrate the teaching, experiment, assessment, question answering and statistics of computer basic course, and realize real-time sharing of related resources and materials. 
Based on the requirements of experimental teaching of computer basic course set out above, the structure diagram of the experimental operation platform of computer basic course as built in this paper is as figure 4 .

\subsection{Teaching design of experimental operation platform}

In this paper, according to the characteristics of IEBOOK software, and for the purpose of arousing students' learning interest, a considerably convenient learning platform is provided, and the teaching design of the experimental operation platform is presented from two aspects, namely system interface and teaching interface. The teaching interface is the most important part of the teaching design of the experimental operation platform. The teaching interface, according to different teaching tasks, consists of four parts: task presentation, task practice, task summarization and curriculum resource sharing.

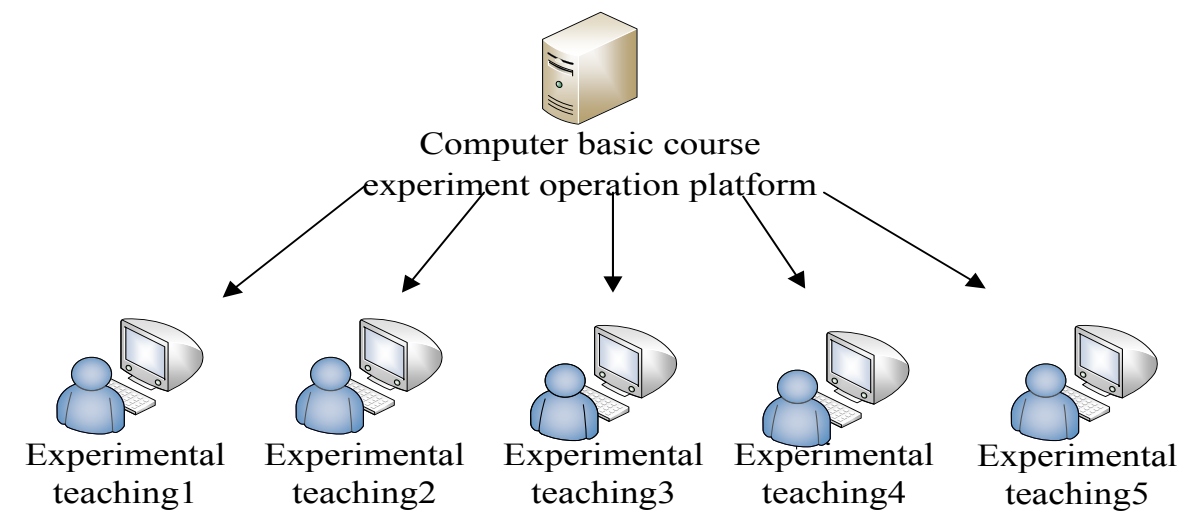

Fig. 4. Functional structure diagram

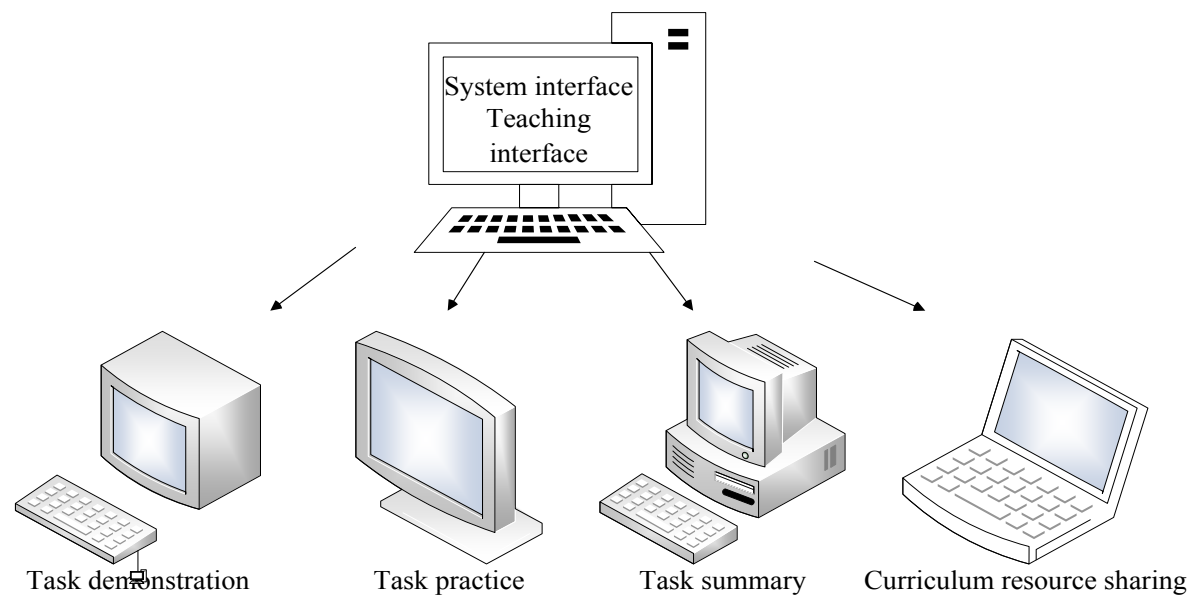

Fig. 5. Structure diagram of audio module 
In this paper, the demonstration process of electronic courseware is combined with the interactive demonstration technology of electronic courseware put forward in Chapter III in the whole task presentation process, and the courseware contents displayed in the whole teaching process are combined with the device for recording touch track, to form a new type of convenient teaching mode. On one hand, electronic courseware prepared with IEBOOK software can be displayed in various forms; on the other hand, it is easy to make annotation and comments or add any contents in the process of electronic courseware demonstration with the interactive demonstration technology. This can largely promote the interaction between teachers and students in the whole teaching process of computer course.

The experimental teaching of computer basic course mainly relates to two aspects:

The first aspect is teaching of foundation courses, which covers fundamental computer operation and basic computer theory. The teaching of foundation courses also covers liberal education of computer course and simple experimental operation. The fundamental operation covers common knowledge of computer application, the usage of common tools of computer, the using base of the internet, and the using base of software, and the basic computer theory covers the operating system theory and brief introduction to the current development tendency of computer and related professional expertise.

The second aspect is teaching of core courses, in particular of advanced application of related software and interpretation of programming language design. For the teaching of core courses, the teaching mode dominated by experiment and supplemented with theories is adopted. Specifically, the teaching covers advanced application of Office software, $\mathrm{C}++$ language programming, Access technology and SQL theoretical basis, Visual Basic language teaching, etc. Heavy teaching tasks are set for this aspect. Such functions of the experimental operation platform of computer basic course based on IEBOOK software of lesson delivery, question answering, and resource sharing are helpful to improve the teaching efficiency of computer basic course.

This experimental operation platform of computer basic course is designed into an comprehensive platform integrating the functions of lesson delivery, question answering and sharing. Fig. 6 shows the demonstration interface of the Basic Course of Applying Goldwave 5.7 in WIN7 on the experimental operation platform. Fig. 7 shows another demonstration interface on the experimental operation platform of computer basic course developed in this research. 


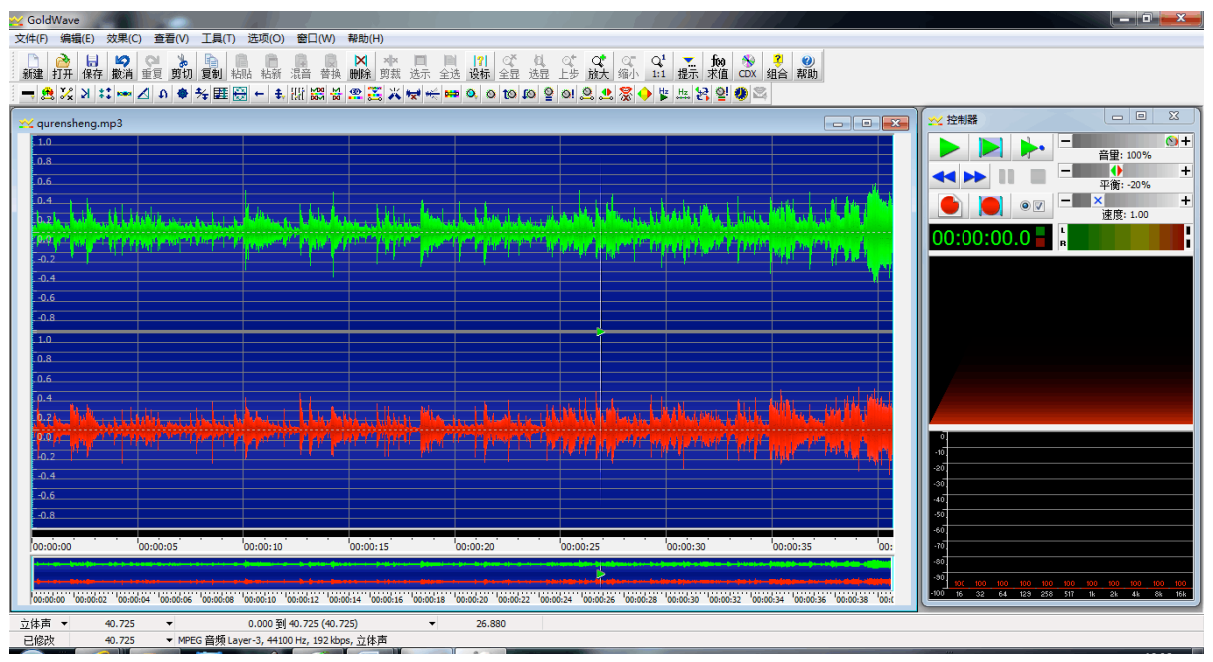

Fig. 6. Demonstration interface of the experimental operation platform

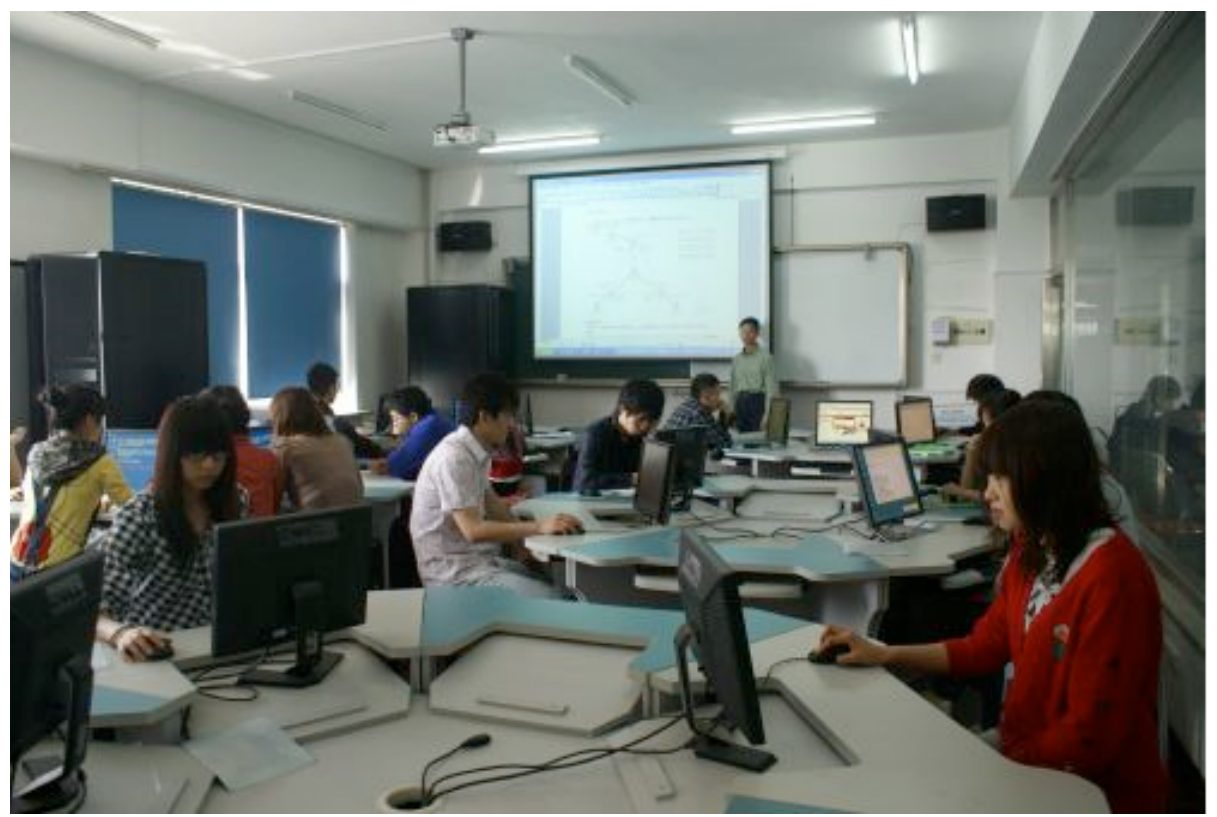

Fig. 7. Demonstration interface of the experimental operation platform of computer basic course II

\subsection{Effect check}

To check the teaching effect of the experimental operation platform of computer basic course, the 84 students (including 69 boys (82.1\%) and 15 girls (17.9\%)) of computer basic course of Grade 2015 were surveyed. For purpose of effect check, the 
84 students finished the computer basic courses of a semester with the experimental operation platform of computer basic course designed in this paper and took certain test. For the test, 84 anonymous questionnaires were handed out, and 84 valid questionnaires were recovered. The collecting rate of questionnaire reaches $100 \%$. According to statistical analysis, the comments given by the students via the survey are as shown in the table 1 .

Table 1. Respondents' comments on the experimental operation platform of computer basic course

\begin{tabular}{|l|c|c|c|}
\hline \multicolumn{1}{|c|}{ Item } & Agree (\%) & Basically agree (\%) & Disagree (\%) \\
\hline Enhance independent learning ability & $76(90.5 \%)$ & $4(4.75 \%)$ & $4(4.75 \%)$ \\
\hline Enhance self-management ability & $72(85.7 \%)$ & $7(8.34 \%)$ & $5(5.96 \%)$ \\
\hline Communication skills & $75(89.3 \%)$ & $6(7.1 \%)$ & $3(3.55 \%)$ \\
\hline Arouse learning interest & $78(92.9 \%)$ & $6(7.1 \%)$ & $0(0 \%)$ \\
\hline Improve operating skill & $78(92.9 \%)$ & $3(3.55 \%)$ & $3(3.55 \%)$ \\
\hline
\end{tabular}

\section{Conclusions}

According to the respondents' comments on the experimental operation platform of computer basic course, they are satisfied with the effect of the operation platform in experimental teaching. $90.5 \%$ and $92.9 \%$ respondents agree that the experimental operation platform is helpful to enhance their independent learning ability and critical thinking ability respectively. They also agree that the IEBOOK-based experimental operation platform is portable, and compatible with mobile devices such as mobile phone and tablet PC, IEBOOK can provide them with an online community similar to BBS where students can interact with teachers via online reading of courseware designed by teachers with this software at any time, and this experimental operation platform presents abundant materials and resources and is combined with the interactive demonstration technology of electronic courseware, which largely enriches the teaching contents.

In a word, the IEBOOK-based experimental operation platform works well in teaching, and can help students give full play to their initiative, cooperation and creativity, which realizes the transformation from receptiveness-oriented teaching into lifelong learning. But it still needs to be further perfected in future teaching practice. We suggest schools to apply the IEBOOK software in development of teaching platform as we did in this research, and create their own electronic journals, to provide students with a platform for development and self-presentation and the public with a window for learning about the schools.

\section{Acknowledgment}

Zhu Zhang is the corresponding author. This work was supported in part by the Higher education research project of Tarim University (TDGJ1724). 


\section{$7 \quad$ References}

[1] Song, W., Dyke, S. Development of a cyber-physical experimental platform for real-time dynamic model updating. Mechanical Systems \& Signal Processing, 2013, vol. 37(1-2), pp. 388-402. https://doi.org/10.1016/j.ymssp.2012.12.007

[2] Piazolo, S., Jessell, M.W., Bons, P.D., et al. Numerical simulations of microstructures using the Elle, platform: A modern research and teaching tool. Journal of the Geological Society of India, 2010, vol. 75(1), pp. 110-127. https://doi.org/10.1007/s12594-010-0028-6

[3] Gonçalves, T., Espíritosanto, A., Ribeiro, B.J.F., et al. A Scalable Hardware Environment for Embedded Systems Education, 2011, vol. 90, pp. 233-245.

[4] Gao, H.H., Zhu, Y.H., Chen, Z.J. Curriculum construction of computer basic experiment teaching based on MOOCs platform. Indusrty and Information Technology Education, 2014, vol. 2(6), pp. 90-94.

[5] Li, X.H. Exploration of University Computer Basic Experiment Teaching Based on cloud space. China Computer \& Communication, 2014, vol. 5, pp. 248-249.

[6] Guan, J.H., Zhang, Y.Q., Wang, Q. Reform and Practice of the Teaching on College Computer Basic Series Courses. Chinese Geological Education, 2008, vol. 17(2), pp. 108-111.

[7] Xia, J. Based on B/S Mode of Higher Vocational Computer Application Basic Experiment Teaching System Design and Development. Computer Knowledge \& Technology, 2016, vol. 12(3), pp. 68-69.

[8] Chi, Z.Z., Hou, G., Lai, X.C., et al. Research of Opening Experimental Construction for Course Group of Computer Organization and Architecture. Research \& Exploration in Laboratory, 2016, vol. 35(1), pp. 150-154.

\section{Authors}

Rong Niu is an associate professor in the College of Information Engineering, Tarim University, Alar 843300, Xinjiang (772278338@qq.com).

Zhu Zhang (Corresponding Author) is a lecturer in the College of Information Engineering, Tarim University, Alar 843300, Xinjiang (772278338@qq.com).

Article submitted 19 March 2017. Published as resubmitted by the authors 25 July 2017. 